With the rules of the game changing before every season, Formula 1 engineers often have a matter of weeks to redesign their car before it is tested on the track. Karl Ziemelis and Charles Wenz join the race to the start line.

hristine Lear's secret is out. As a practical girl, she chose a practical career path, one that suited well her university training in mathematics: she went into computers. Yet something didn't feel right. From an early age Lear has been fascinated by cars. And not just any old cars. Lear's oncesecret obsession is with Formula 1, the pinnacle of high-octane motor racing.

"Working in Formula 1 has always been my dream," she now admits. But even when she got a chance to fulfil that dream - a research position in a university aerodynamics group with close ties to the racing-car industry - she kept her secret to herself. Convinced that it was just wishful thinking, she did not dare confess her hopes, and pursued a $\mathrm{PhD}$ investigating ways to reduce the hazardous airflow patterns that form in an aircraft's wake. Or, as she puts it, "how to land more planes at Heathrow".

But she never lost the excitement she felt during Formula 1 races whenever the commentator referred to 'new aero packages' and other tantalizing revolutions in car performance. She had always wanted to know what lay behind the jargon, and rather than regret never having tried, she finally decided to pursue her childhood ambition.

Lear now has the job of her dreams. In May she joined the Switzerland-based Sauber-Petronas team, with prime responsibility for developing key aerodynamic components on its Formula 1 car. "There was a running joke in the office about my very first job with the team," she recalls. "Take a woman and give her the mirrors." But having proved her worth, she now has a new secret to keep - in this highly competitive industry she is not allowed to divulge the details of projects she is working on.

Academic research has its highs and lows, but there is always some comfort in knowing that the laws of nature underlying your work are likely to be fixed, just waiting to be revealed. If it can be considered a race at all, then it is simply a race to be the first to uncover these inner workings.

The pressures of research in Formula 1
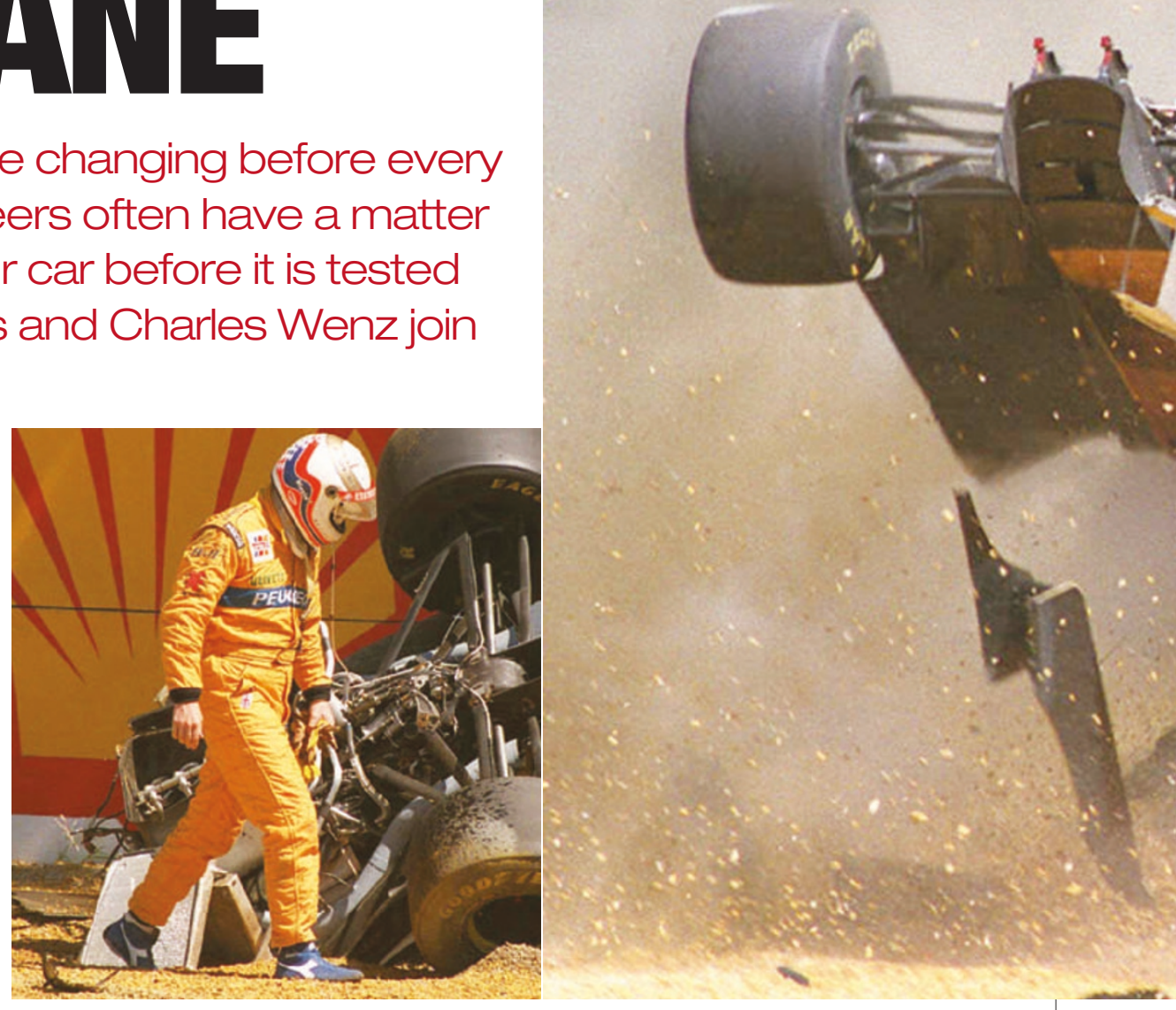

Crash course: engineering teams have significantly improved safety in Formula 1 - even during accidents - and with data from cars on the racetrack (right), they have also boosted performance.

are very different. The laws of nature may be unchangeable, but not so the laws of the sport. The rules under which the teams operate alter from season to season, motivated by a desire to keep car speeds within safe limits while making the cars unpredictable enough to keep drivers - and spectators on their toes. The performance of a car that is hard to handle at speed ultimately depends on the skills of the person behind the wheel, which is why Formula 1 has champions, not mere drivers.

\section{Rapid reactions}

The car designers, of course, have a very different goal. For them, their machine needs to go as fast as is physically possible. It needs to handle like a dream, glued to the road in the tightest of corners. And it needs to win.

Whereas an academic may view the idea of abandoning a cherished line of enquiry with considerable dismay, the same is not true for race engineers. "Rule changes are never a setback," says Peter Bearman, director of aeronautics at Imperial College London and mentor to Lear and numerous other Formula 1 recruits."They relish the challenge."

Willem Toet, senior aerodynamicist with the BAR-Honda Formula 1 team, agrees. Back in the spring of 1994, car performance had reached an all-time high and, over one race weekend, tragically culminated in the deaths of two Formula 1 drivers - Austrian newcomer Roland Ratzenberger and Brazilian champion Ayrton Senna. In their bid to improve car safety, the rule-makers imposed drastic changes to the design specifications, giving the teams only two weeks to comply. By restricting the dimensions of critical aerodynamic components, their aim was to reduce the 'downforce' (and hence speed) that the cars could sustain under race conditions.

Toet remembers the ensuing flurry of activity well. He and his colleagues resorted to cutting away chunks of the finely honed bodywork of their car to crudely bring it into line with the new specifications. The downforce of the butchered machine immediately dropped by $30 \%$. But within a matter of days, redesign and tweaking of the downsized components helped them to recover half of the lost performance, maintaining the car's competitive edge. "Extreme physical and mental work was required - a true intelligence test," says Toet.

This high-pressure environment may 

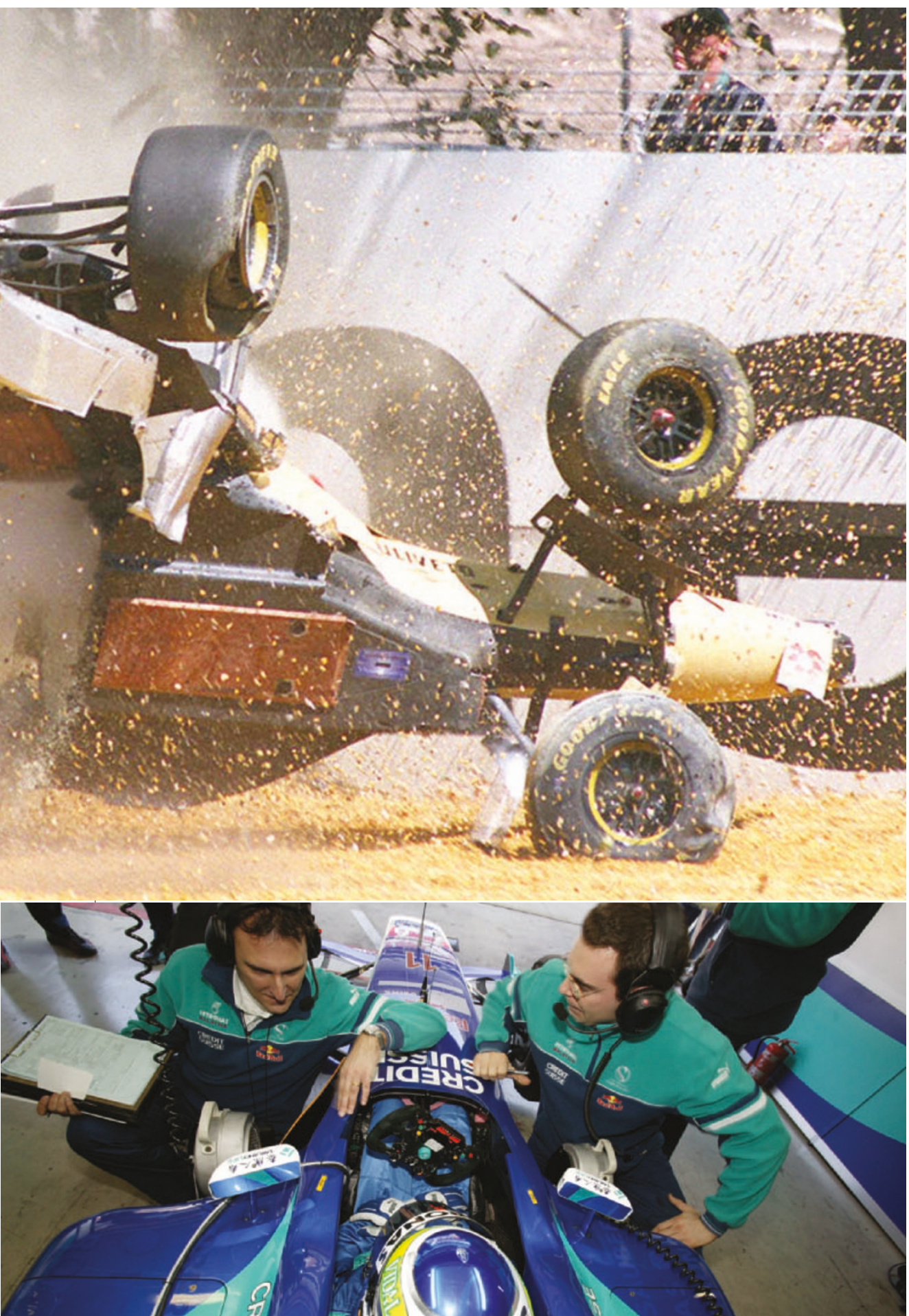

help to explain why Formula 1 recruits heavily from academia. "My last three PhD students all went into Formula 1," says Bearman, whose department has now provided about 40 engineers for the industry. One of his current students, Jonathan Pegrum, is clear about what attracts him to Formula 1. "I want to use what I have learned," says Pegrum, "in aerodynamics, it is hard to think of another industry that is at the cutting edge."

"Many of the people we employ on the engineering side come straight from university," says Nicholas Tombazis, chief aerodynamics engineer at the McLaren-Mercedes
Rewind to the early 1970s. Recognizing its lack of aerodynamic expertise, the Formula 1 industry approached the aeronautics group at Imperial College to help solve a nagging problem: cooling. The cars of that era had a front-mounted radiator, the air from which was funnelled up through the nose of the car and — inconveniently — out through the cockpit. The result? One driver, medium rare.

Solving this problem resulted in a fundamental rethink about the positions of the radiators themselves (they are now sidemounted), followed by a redesign of the car's nose into the now-familiar, and more aerodynamically efficient, pointed shape.

\section{Taming the force}

This was also a time when wind-tunnel techniques underwent rapid development - most notably the introduction of 'rolling roads'. The flow of air around a moving car depends not only on its shape, but also on interactions with the road underneath. To correctly mimic a car moving at speed, the underlying surface needs to move in pace with the flowing air, rather than staying motionless as was previously the case.

A deeper understanding of the interactions between car, air and road led to new ways of exploiting aerodynamic effects. Instead of focusing mostly on drag reduction, engineers discovered that you could make tremendous gains in performance by using aerodynamics to stick the car to the road. This downforce is essentially the reverse of the 'lift' that keeps planes in the air, and is the main role of the 'wings' attached to the nose and rear of the car.

In the 1970s, Lotus engineers realized that the entire car could be made to act like a giant inverted wing if the underside was suitably contoured. This concept became known as the 'ground effect', and led to the introduction of various devices - including roadhugging skirts - to exploit it. Most were then predictably banned. Despite all the rule changes, the combined downforce and ground effect on modern cars would be sufficient, in theory, for them to drive upside down on a ceiling at high speed.

\section{Plane sailing}

But even with these aerodynamic principles firmly in place, designing cars remains a challenge - when it comes to controlling airflow around the chassis, racing cars have a decidedly nasty shape. And the cars have different aerodynamic needs depending on the track conditions - meaning specific features change from race to race. So new aerodynamic ideas will continue to feature heavily in Formula 1 racing, and the teams all now have highly qualified aerodynamicists devoted to the task.

It has been said that a modern Formula 1 car has more in common with a jet fighter than an ordinary road car. But few would 
think of racing car aerodynamics as being more complex still. According to Xin Zhang, an aerodynamicist at the University of Southampton, UK, Formula 1 has pushed the science and engineering expertise in some areas "to a level higher than that of aerospace engineering". In his view, understanding the flow around the streamlined body of an aircraft is straightforward by comparison.

And despite the secretive nature of the Formula 1 industry, the flow of information from aeronautics to racing is beginning to reverse. When Britain's Ministry of Defence began developing the current Harrier fighter jet, the GR.7, it drew on the expertise in composite materials accumulated by Formula 1 engineers.

In Formula 1, everyone likes an accident that people walk away from. Certainly, the race coverage revels in spectacular high-speed accidents from which the drivers emerge relatively unscathed before offering a cheery, yet relieved, wave to the watching fans.

Of course accidents don't happen by design. "We'd far rather the drivers finish the race safely," says Steve Foster, head of composite design at the JaguarCosworth team. But combining a thorough-

bred race car with the drivers' passion for victory results in a heady mix that occasionally ends in catastrophe. Formula 1 drivers are well aware of the risks involved when taking to the track. And behind the scenes, materials scientists such as Foster and O'Rourke are working hard to improve driver safety.

When composite materials made their debut in Formula 1 in the early 1980s, they were little known to the racing industry, and even less understood. As O’Rourke recalls, the teams were keen to exploit materials with high stiffness and low weight — advantages that they had heard about but did not know how to achieve.

Later, when compulsory crash testing of the driver cockpit was introduced in 1988, attention shifted away from stiffness to the more complex material property known as 'strength performance'. This is essential for ensuring driver safety during impact. Today, the composites that make up the cockpit have to survive multiple impact tests before the car is even allowed to race. "Modern composites enable levels of crashworthiness and protection that would be impossible to achieve with traditional materials," says Foster.

Despite these successes, working with these materials is too often a black art, and this is where the team has its work cut out.

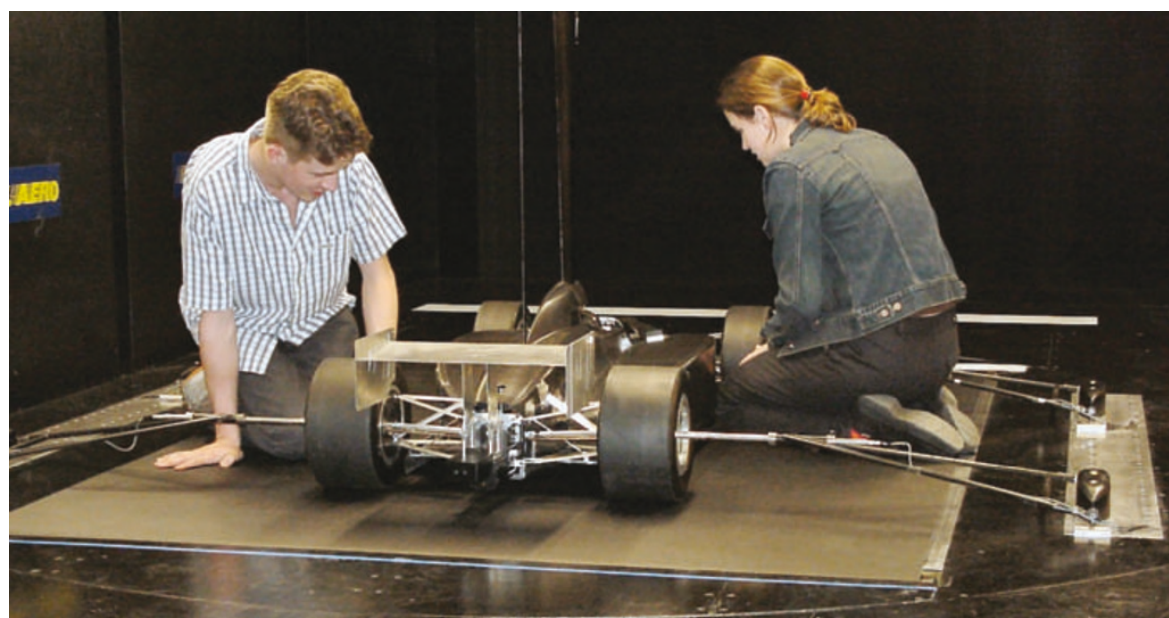

It's a blast: aerodynamics students assess a racing prototype in a wind tunnel at Imperial College.

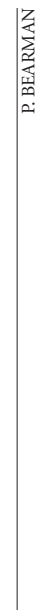

It's ablast:aerodynamics students assess a racing prototype in a wind tumnel at Imperial College.

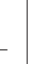
from the rapid returns. In contrast to the sedentary pace of university research, development of a Formula 1 car takes place at a breakneck speed. "What I am working on right now could appear on the car in a race or two," she says. Barney Garrood, a recent recruit to the Ferrari team, says that this was a key factor in his decision to make the move from academia. "Research in the aerospace sector is static in comparison, with typical development times of 10 to 15 years," he says. "This is much more exciting."

Then there are the resources. The multimillion-dollar budgets behind a Formula 1 team would be the envy of most research groups. No surprise then that Bearman refers to the McLaren Technology Centre in Woking, UK, as "a temple to technology". With its sweeping architecture and stateof-the-art facilities, this striking establishment was designed to inspire. "McLaren wanted to create an environment that will motivate and influence people who work within it," says Tombazis.

For Lear and her former academic colleagues, gone are the frustrations of limited technical support, or killing time while waiting for a slot on a university's over-subscribed facilities. These young guns now find themselves immersed in a continuous and rapid cycle of designing, building and testing. "The aim is to have new parts on the car for every race," says Lear.

And like most researchers, those in Formula 1 get a kick from knowing their work makes a difference. The goals may be more limited in a strict scientific sense, but the work has more immediacy than in almost any other field of enquiry. "Being able to point to your own parts on a car — and then seeing that car win a race - is a real thrill," says Garrood.

And for Lear, perhaps the biggest thrill of all comes from having realized her dream. In a secretive profession, this is one secret that she is more than happy to share.

Karl Ziemelis and Charles Wenz are Nature's resident petrolheads. 